\title{
Uso e diversidade de plantas medicinais da Caatinga na comunidade rural de Laginhas, município de Caicó, Rio Grande do Norte (nordeste do Brasil)
}

ROQUE, A.A. ${ }^{1 *}$; ROCHA, R.M. ${ }^{2}$; LOIOLA, M.I.B. ${ }^{1}$

${ }^{1}$ Universidade Federal do Rio Grande do Norte, Programa Regional de Pós-graduação em Desenvolvimento e Meio Ambiente (PRODEMA/UFRN), Herbário UFRN, Departamento de Botânica, Ecologia e Zoologia, Campus Universitário, Lagoa Nova, CEP:59720-970, Natal-Brasil. *alan.ufrn@gmail.com ${ }^{2}$ Departamento de História e Geografia, UFRN, CEP:593000-000, Caicó-Brasil

RESUMO: O presente trabalho teve como objetivo identificar as formas de uso de plantas medicinais nativas do bioma Caatinga, em comunidade rural no município de Caicó, Rio Grande do Norte (Nordeste do Brasil). Utilizaram-se entrevistas semi-estruturadas e estruturadas buscando informações, junto a especialistas locais, sobre o uso das plantas. São descritos os usos medicinais de 62 espécies, reportadas por 12 informantes (mateiros, rezadeiras, raizeiros, agricultores e donas-de-casa) com idade superior a 35 anos. As famílias com maior representatividade na consulta foram Fabaceae (13 spp.), Euphorbiaceae (6 spp.) Cactaceae (3 spp.) e Lamiaceae (3 spp.). Para revelar as espécies mais importantes foi considerado o grau de consenso entre as respostas dos informantes. Aaroeira (Myracrodruon urundeuva Allemão) e 0 cumaru (Amburana cearensis (Allemão) A. C. Sm.) destacaram-se como as espécies com o maior número de citações, sendo estas também as que obtiveram o maior número de indicações de usos terapêuticos. As cascas e as raízes foram as partes predominantemente consumidas. Os dados levantados por esta pesquisa evidenciaram uma diversidade de espécies da flora seridoense com potencial medicinal e reforçama importância que a biodiversidade tem sobre as comunidades rurais, viabilizando o início do estudo de manejo da vegetação local.

Palavras-chave: Caatinga, comunidade rural, etnobotânica, plantas medicinais, Rio Grande do Norte

\begin{abstract}
Use and diversity of medicinal plants from Caatinga in the rural community of Laginhas, Caicó Municipality, Rio Grande do Norte State (Northeast of Brazil). The present study aimed to identify the different uses of medicinal plants native to Caatinga biome in a rural community from Caicó Municipality, Rio Grande do Norte State, Brazil. Semi-structured and structured interviews with local specialists were used to collect information about the use of such plants. The medicinal uses of 62 species were described by 12 informants (woodsmen, faith healers, herb doctors, farmers and housewives) older than 35 years. The most representative families reported in the survey were Fabaceae (13 spp), Euphorbiaceae (6 spp.), Cactaceae (3 spp.), and Lamiaceae (3 spp.). The degree of consensus among responses was adopted to determine the most important species. The species "aroeira" (Myracrodruon urundeuva Allemão) and "cumaru" (Amburana cearensis (Allemão) A. C. Sm.) were most frequently mentioned and indicated for therapeutic uses. Barks and roots were the most consumed parts. The data obtained in this study indicated a diversity of flora species with medicinal potential in Seridó region (Rio Grande do Norte State) and reinforced the importance of biodiversity in rural communities, starting the study on the local vegetation management.
\end{abstract}

Key words: Caatinga, rural community, ethnobotany, medicinal plants, Rio Grande do Norte

Recebido para publicação em 04/11/2008

Aceito para publicação em 10/11/2009

Rev. Bras. PI. Med., Botucatu, v.12, n.1, p.31-42, 2010. 


\section{INTRODUÇÃO}

O ser humano foi e ainda é, importante agente de mudanças vegetacionais e de evolução vegetal, porque sempre foi dependente do meio botânico para a sobrevivência, manipulando-o não somente para suprir as necessidades mais urgentes, mas também na magia e medicina, no uso empírico ou simbólico, nos ritos gerenciadores da vida e mantenedores da ordem social (Albuquerque, 2005).

As comunidades rurais estão intimamente ligadas aos usos de planas medicinais, por estas serem, na maioria das vezes, o único recurso disponível para o tratamento de doenças na região. Para Pilla et al. (2006), à medida que a relação com a terra passa por uma modernização e o contato com centros urbanos se intensifica, a rede de transmissão do conhecimento sobre plantas medicinais pode sofrer alterações, sendo necessário com urgência fazer o resgate deste conhecimento e das técnicas terapêuticas, como uma maneira de deixar registrado este modo de aprendizado informal.

A caatinga, bioma exclusivamente brasileiro, é uma das vegetações mais ameaçadas do planeta, e, apesar disto, esta exclusividade não foi suficiente para direcionar muitos estudos botânicos nesta área (Brasil, 2002). Vários autores (Albuquerque \& Andrade, 2002a; Albuquerque \& Lucena, 2004) chamam a atenção para o fato de que as populações distribuídas dentro deste bioma, na maioria, dependem diretamente dos recursos vegetais disponíveis para o sustento.

A partir de levantamentos das potencialidades dos recursos vegetais disponíveis a uma determinada comunidade, pode-se traçar planos de recuperação e de conservação da área estudada, assim como a otimização dos usos originais atribuídos pelos moradores, complementando a renda da população ao mesmo tempo em que se ampliariam as perspectivas das gerações futuras usufruírem destes recursos.

Segundo Diegues (2000), a importância de trabalhos que contemplem o conhecimento tradicional, se encontra na diferença do termo "biodiversidade" que, na maioria das vezes, é traduzida em longas listas de espécies de plantas e animais descontextualizados do domínio cultural, para a "biodiversidade" em grande parte construída e apropriada material e simbolicamente pelas populações tradicionais. Quando se une o natural e - cultural, obtêm-se espécies de maior valor simbólico, onde fica mais viável lutar pela conservação.

O objetivo do presente trabalho foi realizar o estudo etnobotânico de espécies vegetais nativas utilizadas como plantas medicinais por especialistas locais da comunidade rural de Laginhas, município de Caicó - RN. Para tanto foram investigados 1) as partes das plantas utilizadas;2) as principais doenças combatidas; 3 ) a forma de preparo dos medicamentos caseiros e 4) os índices de concordância de uso entre os entrevistados.

\section{MATERIAL E MÉTODO}

A comunidade rural de Laginhas (0614‘59"S; 370ㅜㄷㄴ'W) está localizada no Nordeste brasileiro, no município de Caicó, Rio Grande do Norte (Figura 1). Situa-se na região denominada Seridó Potiguar, distando 26 km do centro urbano de Caicó e 306 km da capital do Estado. O clima é do tipo Bshw de Köppen, semi-árido quente e seco comcurta estação chuvosa (trimestre março/abril/maio), 500 a $800 \mathrm{~mm}$ anuais, temperaturas elevadas média de $30^{\circ} \mathrm{C}$ (VarelaFreire, 2002). Avegetação natural apresenta-se com formações lenhosas de baixo a médio porte e grande representatividade de espécies xerófitas e decíduas, onde predomina um tipo especial de Caatinga denominada Savana-Estépica Gramíneo-Lenhosa, que possui estrato herbáceo bastante definido em épocas de chuvas (IBGE, 1992).

Nesta comunidade residem 434 habitantes, sendo 214 homens e 220 mulheres (IBGE, 2000). Esta população, na maioria, vive de economia de subsistência, cultivando nas vazantes de açudes, plantas como milho (Zea mays L.), feijão (Phaseolus vulgaris L.), batata-doce (Ipomoea batatas L.) e jerimum (Cucurbita maxima Duchesne). Destaca-se também nessa área e entorno, a criação de gado bovinos e caprinos. Uma parte significativa da vegetação é derrubada para a criação de pastagens e para a produção de carvão.

A comunidade rural de Laginhas situa-se vizinha a uma unidade de conservação ambiental e esta tem relevante papel nas práticas de uso vegetal da comunidade. AReserva Particular do Patrimônio Natural Stoessel de Britto (0612'54.7' S;

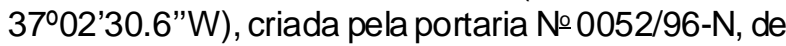
20 de maio de 1994, possui área de 755,95 hectares e localiza-se ao sul do município de Jucurutu, distando apenas $3 \mathrm{Km}$ de Laginhas (Figura 1).

A coleta de dados foi feita mensalmente na comunidade rural de Laginhas no período de março/ 2007 a maio/2008, incluindo dentro deste intervalo uma estação seca e uma chuvosa. Utilizaram-se observação participante, entrevistas semi-estruturadas e estruturadas (Albuquerque \& Lucena, 2004), buscando obter informações sobre o potencial medicinal e características botânicas das plantas utilizadas.

Foram entrevistadas 11 mulheres (na faixa etária dos 36 aos 81 anos) e apenas 01 homem (com 56 anos), considerados pela comunidade como especialistas locais (mateiros, rezadeiras, raizeiros, agricultores, donas-de-casa). O grau de escolaridade da maioria dos entrevistados encontra-se entre as quatro primeiras séries do Ensino Fundamental, e as suas 


\section{Localização do Distrito de Laginhas - Caicó, RN e RPPN Stoessel de Britto - Jucurutu, RN}
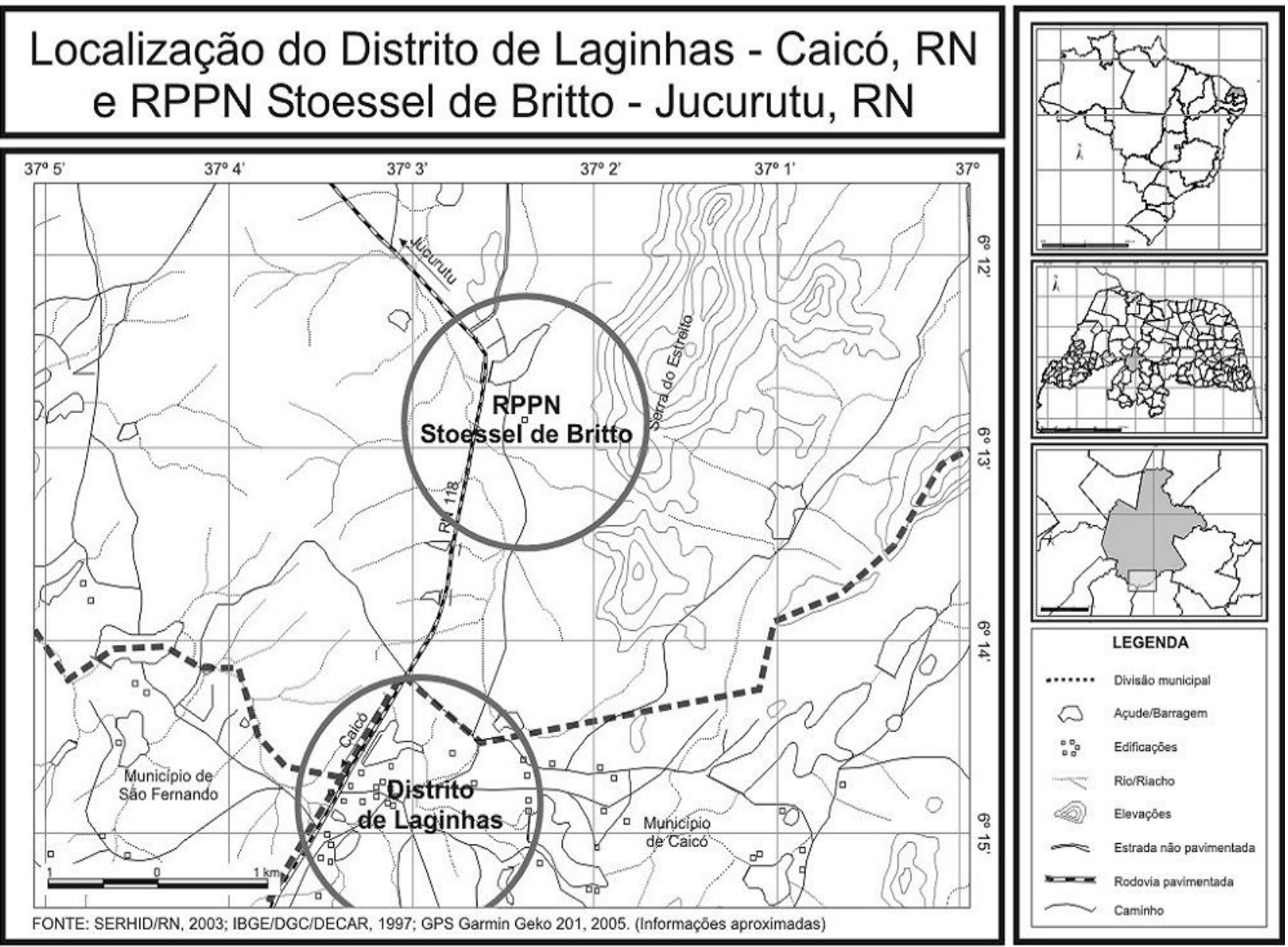

FIGURA 1. Limites dos municípios de Jucurutu e Caicó, evidenciando a comunidade rural de Laginhas e a RPPN Stoessel de Britto, estado do Rio Grande do Norte, Nordeste do Brasil.

vidas estão todas ligadas a práticas agrícolas como já enfatizado anteriormente. Na maioria moramem casa de tijolos, sem saneamento básico. Apopulação dispõe ainda do atendimento de um Posto de Saúde, onde são realizadas consultas em dias alternados.

Como técnica de amostragem utilizou-se a metodologia proposta por Bailey (1994), chamada "bola de neve"(snow ball), onde o primeiro especialista entrevistado indica o próximo, de modo que, ao final do estudo todos os especialistas da comunidade são entrevistados.

As principais questões levantadas aos informantes levaram em consideração o uso medicinal das plantas pela comunidade, as principais doenças combatidas, formas de preparo dos medicamentos e coleta das partes vegetais usadas. Foi questionada ainda a visão futura das práticas etnobotânicas dentro desta comunidade.

Como parte complementar desta etapa, realizaram-se idas a campo para coleta de amostras botânicas na companhia de um ou mais entrevistados. Este procedimento conhecido por "turnê-guiada" é utilizado para se evitar erros na identificação, advindos dos nomes vernaculares das plantas, pois o informante aponta in Ioco, a espécie citada (Albuquerque \& Lucena, 2004).

Foram coletadas amostras botânicas férteis (com flor, fruto) a fim de se obter a identificação e informações mais precisas sobre as espécies indicadas. Foram anotadas, simultaneamente, todas as características do espécime em uma caderneta de campo (hábito, altura da planta, coloração de flores e frutos). Em seguida, foi feito todo processo de herborização proposto por Mori et al. (1989) e Bridson \& Forman (1998). A identificação das amostras botânicas coletadas foi obtida através de consultas a bibliografias especializadas, utilização de chaves de identificação e comparações morfológicas com exsicatas já identificadas no Herbário UFRN da Universidade Federal do Rio Grande do Norte, onde posteriormente, toda a coleção resultante desse estudo foi incorporada. O material não identificado foi enviado a especialistas. A classificação das famílias foi baseada emAPG II (2003) e os nomes científicos das espécies estão de acordo como site MOBOT (2008).

De acordo com a Classificação Estatística 
Internacional de Doenças e Problemas Relacionados à Saúde (OMS, 2000), as doenças e sintomas tratados por plantas medicinais pelos entrevistados da comunidade rural de Laginhas, foram separados em categorias, viabilizando assima tabulação dos dados.

Foram calculadas a concordância quanto aos usos principais (CUP) e a correção para freqüência de citação das espécies (CUPc), visando identificar as espécies mais representativas para os entrevistados (Amorozo \& Gély, 1988).

\section{RESULTADO E DISCUSSÃO}

Os especialistas locais da comunidade rural de Laginhas citaram 62 espécies nativas com potencial medicinal, que estão distribuídas em 55 gêneros e 33 famílias (Tabela 1). As famílias com maior representatividade foram Fabaceae (13 spp.), Euphorbiaceae (6 spp.), Cactaceae (3 spp.) e Lamiaceae (3 spp.). Embora não se tenha, até o momento, registro(s) de trabalho(s) enfocando plantas medicinais no Rio Grande do Norte, deve-se ressaltar que nos levantamentos florísticos no semi-árido potiguar, Fabaceae, Euphorbiaceae e Cactaceae são apontadas como as famílias mais representativas em número de espécies (Camacho, 2001; Queiroz, 2006).

Também não foi encontrado para a região Nordeste, nenhum estudo tratando especificamente sobre o uso medicinal de espécies nativas ocorrentes na Caatinga. Porém observou-se que em trabalhos de plantas medicinais realizados neste bioma, especialmente no estado de Pernambuco, onde foram consideradas tanto espécies nativas como introduzidas, o número de espécies nativas é relativamente baixo. Das 48 plantas relacionadas por Albuquerque \& Andrade (2002b) para área de Caatinga no agreste pernambucano, 34 eram nativas; enquanto no estudo realizado no município de Jupi por Teixeira \& Melo (2006), das 106 espécies reportadas apenas 27 eramnativas da região. Já Florentino et al. (2007) verificaram que das 84 espécies no município de Caruaru, 28 representavamplantas nativas. O número relativamente alto de espécies nativas com uso medicinal no presente trabalho (62) deve-se ao fato de que, o objeto de estudo enfocou somente as plantas nativas.

A Tabela 1 apresenta a lista de espécies usadas para fins medicinais na comunidade rural de Laginhas, o número de informantes que citaram usos para estas espécies e quantos usos diferentes foram reconhecidos para cada espécie.

Entre as plantas indicadas como medicinais, destacaram-se a aroeira (Myracrodruon urundeuva Allemão) e o cumaru (Amburana cearensis (Allemão) A.C.Sm.) como as espécies como maior número de citações, sendo estas também as que obtiveram o maior número de indicações de usos terapêuticos.
Ao verificar o índice de concordância de uso principal (CUP) de algumas espécies (Tabela 2) como marmeleiro (Croton blanchetianus), quebra pedra (Phyllanthus niruri) e carrapicho-cigano (Acanthospermum hispidum), constatou-se que essa porcentagem foi muito alta (todos em 100\%), porém, vale salientar que a quantidade de informantes indicando uso para estas espécies foi abaixo ou igual a 07 pessoas. Quando se calcula o CUPc este valor caí, pois é relativo à espécie mais citada pelos informantes, que neste caso corresponde a aroeira (Myracrodruon urundeuva) e o cumaru (Amburana cearensis), que obtiveram 12 citações cada. Desta forma, espécies como o carrapicho-cigano (Acanthospermum hispidum) que é utilizado para o combate de doenças respiratórias e que teve seu CUP em $100 \%$, sendo seu valor de concordância corrigido (CUPc) para $41,7 \%$. Estes dados auxiliam na comprovação da eficácia de determinada espécie para o uso medicinal. Quanto mais informantes concordarem com determinado uso, mais haverá a validação destas informações que, no futuro, poderão servir de base para estudos farmacológicos, buscando a descoberta de novas curas para doenças e/ou a melhoria de medicamentos já existentes.

Devida atenção deve estar voltada para a espécie que está relacionada na Tabela 2 , a aroeira (Myracrodruon urundeuva), uma vez que a mesma está incluída na "Lista Oficial da Flora Brasileira Ameaçada de Extinção" (Brasil, 2008). Esta árvore que é apontada como a mais usada pela comunidade de Laginhas, têm o uso vinculado a retirada das cascas, que na maioria das vezes interfere no desenvolvimento da planta, podendo levá-la à morte .

A presente pesquisa deu ênfase às espécies nativas do Nordeste, na tentativa de entender a interrelação da população com as plantas nativas, por estas não serem herdeiras de outras culturas, e estaremligadas somente às crenças locais. Trabalhos como o de Albuquerque \& Andrade (2002a) demonstram ainda a importância de se desenvolver estudos sistemáticos com as plantas nativas de uma dada região, podendo estes identificar problemas ocasionados pelos maus usos dos recursos vegetais disponíveis, uma vez que, a partir destas informações, podem-se oferecer alternativas eficazes que diminuam o impacto da coleta sobre as populações naturais.

Por se tratar de um trabalho com plantas da Caatinga levou-se em consideração que, a disponibilidade desses recursos e atendimento das necessidades da comunidade obedecem a fatores temporais. Aflora da região seridoense está adaptada ao seu recorte geográfico: clima quente e seco, solos rasos e pedregosos e longo período sem chuva. Isso significa que a maioria das espécies do componente herbáceo não está disponível o ano todo para as comunidades. 
TABELA 1. Espécies usadas para fins medicinais pela comunidade rural de Laginhas (Caicó, RN). Convenções: Voucher (Herbário UFRN); ICUE = informantes citando usos das espécies; NUC = número de usos citados para cada espécie.

\begin{tabular}{|c|c|c|c|c|c|}
\hline Família/Nome Científico & Nome Vulgar & Voucher & Hábito & ICUE & NUC \\
\hline \multicolumn{6}{|l|}{ PTERIDOPHYTA } \\
\hline \multicolumn{6}{|l|}{ SELAGINELLACEAE } \\
\hline Selaginella convoluta (Arn.) Spring & mão-fechada & 7261 & erva & 4 & 2 \\
\hline \multicolumn{6}{|l|}{ ANGIOSPERMAE } \\
\hline \multicolumn{6}{|l|}{ ALISMATACEAE } \\
\hline Echinodorus subalatus (Mart.) Griseb & língua-de-vaca & 5452 & erva & 1 & 2 \\
\hline \multicolumn{6}{|l|}{ AMARANTHACEAE } \\
\hline Chenopodium ambrosioides $\mathrm{L}$. & mastruz & 7727 & erva & 5 & 8 \\
\hline Gomphrena demissa Mart. & capitãozinho & 4096 & erva & 10 & 7 \\
\hline \multicolumn{6}{|l|}{ ANACARDIACEAE } \\
\hline Myracrodruon urundeuva Allemão & aroeira & 5522 & árvore & 12 & 10 \\
\hline \multicolumn{6}{|l|}{ APOCYNACEAE } \\
\hline Aspidosperma pyrifolium Mart. & pereiro & 6393 & árvore & 1 & 1 \\
\hline \multicolumn{6}{|l|}{ ARECACEAE } \\
\hline Copernicia cerifera (Arruda) Mart. & carnaúba & 7726 & árvore & 2 & 1 \\
\hline \multicolumn{6}{|l|}{ ASTERACEAE } \\
\hline Acanthospermum hispidum DC. & $\begin{array}{l}\text { carrapicho- } \\
\text { cigano }\end{array}$ & 7723 & erva & 5 & 2 \\
\hline Egletes viscosa (L.) Less. & macela & 6681 & erva & 1 & 1 \\
\hline \multicolumn{6}{|l|}{ BIGNONIACEAE } \\
\hline Tabebuia impetiginosa (Mart. ex DC.) Standl. & pau -d'arco roxo & 8036 & árvore & 3 & 6 \\
\hline \multicolumn{6}{|l|}{ BORAGINACEAE } \\
\hline Heliotropium elongatum Willd. & fedegoso & 6396 & erva & 11 & 4 \\
\hline \multicolumn{6}{|l|}{ BRASSICACEAE } \\
\hline Capparis cynophallophora L. & feijão-bravo & 6387 & arbusto & 1 & 1 \\
\hline Cleome spinosa Jacq. & mussambê & 4077 & erva & 10 & 3 \\
\hline \multicolumn{6}{|l|}{ BURSERACEAE } \\
\hline Commiphora leptophloeos (Mart.) J.B. Gillett & imburana & 6395 & árvore & 1 & 1 \\
\hline \multicolumn{6}{|l|}{ CACTACEAE } \\
\hline Cereus jamacaru DC. & mandacaru & 6658 & arbusto & 4 & 3 \\
\hline Melocactus sp. & coroa-de-frade & - & erva & 6 & 7 \\
\hline $\begin{array}{l}\text { Pilosocereus gounellei (F.A.C. Weber) Byles } \\
\text { \& G.D. Rowley } \\
\text { CHRYSOBALANACEAE }\end{array}$ & xique-xique & 6659 & arbusto & 1 & 1 \\
\hline Licania rigida Benth & oiticica & 7582 & árvore & 1 & 2 \\
\hline \multicolumn{6}{|l|}{ COMBRETACEAE } \\
\hline Combretum leprosum Mart. & mofumbo & 4104 & arbusto & 2 & 1 \\
\hline \multicolumn{6}{|l|}{ CONVOLVULACEAE } \\
\hline Ipomoea asarifolia (Desr.) Roem. \& Schult. & salsa & 8039 & erva & 4 & 3 \\
\hline Operculina macrocarpa (Linn) Urb. & batata-de-purga & 7967 & trepadeira & 10 & 7 \\
\hline \multicolumn{6}{|l|}{ CUCURBITACEAE } \\
\hline Apodanthera congestiflora Cogn. & cabeça-de negro & 7660 & trepadeira & 7 & 8 \\
\hline Luffa operculata (L.) Cogn. & cabacinha & - & trepadeira & 7 & 6 \\
\hline
\end{tabular}

Rev. Bras. PI. Med., Botucatu, v.12, n.1, p.31-42, 2010. 
TABELA 1. Espécies usadas para fins medicinais pela comunidade rural de Laginhas (Caicó, RN). Convenções: Voucher (Herbário UFRN); ICUE = informantes citando usos das espécies; NUC = número de usos citados para cada espécie.

continuação

\begin{tabular}{|c|c|c|c|c|c|}
\hline Família/Nome Científico & Nome Vulgar & Voucher & Hábito & ICUE & NUC \\
\hline \multicolumn{6}{|l|}{ CUCURBITACEAE } \\
\hline Apodanthera congestiflora Cogn. & cabeça-de negro & 7660 & trepadeira & 7 & 8 \\
\hline Luffa operculata (L.) Cogn. & cabacinha & - & trepadeira & 7 & 6 \\
\hline \multicolumn{6}{|l|}{ CYPERACEAE } \\
\hline Cyperus articulatus $\mathrm{L}$. & junco & 6686 & erva & 4 & 4 \\
\hline Fimbristylis vahlii (Lam.) Link & barba-de-bode & 7687 & erva & 2 & 1 \\
\hline \multicolumn{6}{|l|}{ EUPHORBIACEAE } \\
\hline Cnidoscolus quercifolius Pohl & favela & 6389 & árvore & 7 & 3 \\
\hline Cnidoscolus urens (L.) Arthur & urtiga & 7301 & subarbusto & 5 & 5 \\
\hline Croton blanchetianus Baill. & marmeleiro & 4072 & arbusto & 7 & 3 \\
\hline Croton heliotropiifolius Kunth. & velame & 2802 & arbusto & 3 & 4 \\
\hline Croton sp. & $\begin{array}{l}\text { marmeleiro- } \\
\text { branco }\end{array}$ & - & arbusto & 1 & 1 \\
\hline Jatropha mollissima (Pohl) Baill. & pinhão-brabo & 6679 & arbusto & 5 & 4 \\
\hline \multicolumn{6}{|l|}{ FABACEAE } \\
\hline \multicolumn{6}{|l|}{ Caesalpinioideae } \\
\hline Caesalpinia ferrea Mart. & jucá & 7730 & árvore & 7 & 6 \\
\hline Caesalpinia pyramidalis Tul. & catingueira & 4103 & árvore & 5 & 3 \\
\hline Senna obtusifolia (L.) H.S. Irwin \& Barneby & mata-pasto & 7724 & erva & 1 & 1 \\
\hline Senna ocidentallis (L.) Link & manjerioba & 6670 & erva & 2 & 2 \\
\hline \multicolumn{6}{|l|}{ Cercideae } \\
\hline Bauhinia cheilantha (Bong.) Steud. & mororó-preto & 4099 & arbusto & 2 & 1 \\
\hline Bauhinia pentandra(Bong.) Vogel ex Steud. & mororó-branco & 4069 & arbusto & 3 & 6 \\
\hline \multicolumn{6}{|l|}{ Faboideae } \\
\hline Amburana cearensis ( Allemão) A.C.Sm. & cumaru & 7928 & árvore & 12 & 10 \\
\hline Dioclea grandiflora Mart. ex Benth. & mucunã & 8025 & trepadeira & 4 & 3 \\
\hline Erythrina velutina Willd. & mulungu & 7725 & árvore & 1 & 1 \\
\hline Geoffroea spinosa Jacq. & umarizeiro & - & árvore & 1 & 1 \\
\hline Myroxylon peruiferum L. f. & brejuí & 5524 & árvore & 4 & 5 \\
\hline \multicolumn{6}{|l|}{ Mimosoideae } \\
\hline Anadenanthera colubrina (Vell.) Brenan & angico & 6622 & árvore & 8 & 8 \\
\hline Mimosa tenuiflora (Willd.) Poir. & jurema-preta & 6383 & árvore & 11 & 7 \\
\hline \multicolumn{6}{|l|}{ LAMIACEAE } \\
\hline Hyptis suaveolens (L.) Poit. & alfazema-braba & 7581 & erva & 9 & 7 \\
\hline Marsypianthes chamaedrys (Vahl) Kuntze & betônica & 7511 & erva & 1 & 1 \\
\hline Vitex gardneriana Schauer & jaramataia & 7506 & árvore & 8 & 8 \\
\hline \multicolumn{6}{|l|}{ MALVACEAE } \\
\hline $\begin{array}{l}\text { Pseudobombax marginatum (A. St.-Hil., Juss. } \\
\text { \& Cambess.) A. Robyns } \\
\text { NYCTAGINACEAE }\end{array}$ & embiratã & 5449 & árvore & 1 & 1 \\
\hline Boerhavia diffusa L. & pega-pinto & 6652 & erva & 5 & 3 \\
\hline
\end{tabular}


TABELA 1. Espécies usadas para fins medicinais pela comunidade rural de Laginhas (Caicó, RN). Convenções: Voucher (Herbário UFRN); ICUE = informantes citando usos das espécies; NUC = número de usos citados para cada espécie.

continuação

\begin{tabular}{|c|c|c|c|c|c|}
\hline Família/Nome Científico & Nome Vulgar & Voucher & Hábito & ICUE & NUC \\
\hline \multicolumn{6}{|l|}{ OLACACEAE } \\
\hline Ximenia americana L. & ameixa & 6388 & arbusto & 7 & 6 \\
\hline \multicolumn{6}{|l|}{ PASSIFLORACEAE } \\
\hline Passiflora foetida L. & $\begin{array}{l}\text { maracujá-do- } \\
\text { mato }\end{array}$ & 4071 & trepadeira & 1 & 1 \\
\hline \multicolumn{6}{|l|}{ PHYLLANTHACEAE } \\
\hline Phyllanthus niruri L. & quebra-pedra & 7732 & erva & 6 & 3 \\
\hline \multicolumn{6}{|l|}{ PLANTAGINACEAE } \\
\hline Scoparia dulcis L. & vassourinha & 6631 & erva & 10 & 8 \\
\hline \multicolumn{6}{|l|}{ POLYGONACEAE } \\
\hline Triplaris gardneriana Wedd. & cauaçú & - & árvore & 2 & 1 \\
\hline \multicolumn{6}{|l|}{ RHAMNACEAE } \\
\hline Ziziphus joazeiro Mart. & juazeiro & 4049 & árvore & 9 & 8 \\
\hline \multicolumn{6}{|l|}{ RUBIACEAE } \\
\hline $\begin{array}{l}\text { Tocoyena formosa (Cham. \& Schltdl.) K. } \\
\text { Schum. }\end{array}$ & genipapo & 6675 & árvore & 1 & 1 \\
\hline Guettarda angelica Mart. ex Müll.Arg. & quina-da-serra & 4108 & arbusto & 1 & 1 \\
\hline \multicolumn{6}{|l|}{ SAPOTACEAE } \\
\hline $\begin{array}{l}\text { Sideroxylon obtusifolium (Humb. ex Roem. \& } \\
\text { Schult.) T.D.Penn. } \\
\text { SOLANACEAE }\end{array}$ & quixabeira & 5523 & árvore & 8 & 8 \\
\hline Solanum agrarium Sendtn. & $\begin{array}{l}\text { melancia-da- } \\
\text { praia }\end{array}$ & & erva & 4 & 5 \\
\hline Solanum sp. & jurubeba & - & erva & 1 & 3 \\
\hline \multicolumn{6}{|l|}{ TURNERACEAE } \\
\hline Turnera subulata Sm. & chanana & 6654 & erva & 10 & 9 \\
\hline \multicolumn{6}{|l|}{ VIOLACEAE } \\
\hline Hybanthus calceolaria (L.) Oken & $\begin{array}{l}\text { papacunha, } \\
\text { ipepacunha }\end{array}$ & - & erva & 4 & 5 \\
\hline
\end{tabular}

As ervas e árvores constituíramas principais fontes de consumo dos entrevistados, com $37 \%$ e $34 \%$ de representatividade, seguidos pelos arbustos com $21 \%$ e as trepadeiras com apenas $8 \%$. As ervas também foram listadas por Santos et al. (2008) como as mais predominantes, correspondendo a $63 \%$ das espécies registradas com potencial medicinal na comunidade rural da Vargem Grande no município de Natividade da Serra, SP. Já Albuquerque \& Andrade (2002b) ao estudar o uso dos recursos vegetais em uma área de Caatinga em Pernambuco verificaram que as árvores e arbustos foram as principais fontes de recursos. Vale ressaltar que esses autores consideraram diferentes categorias de uso e que esta pode ser a provável explicação para essa divergência. Acredita-se que o elevado número de citações de herbáceas no presente levantamento, considerando que estas ocorrem com maior freqüência apenas no curto período das chuvas (geralmente janeiro-março), deveu-se a três fatores: a) facilidade de coleta das plantas; b) o surgimento das doenças respiratórias coincide com o período chuvoso e é nesta época do ano, que as ervas estão mais disponíveis e c) algumas espécies herbáceas são infestantes de lavouras, que por conter uso específico são toleradas pelos agricultores.

Ressalta-se ainda que algumas espécies arbóreas como brejuí (Myroxylon peruiferum)e aroeira (Myracroduon urundeuva) já são escassas na comunidade e isso tem feito com que alguns raizeiros e mateiros locais façam uso da vegetação da RPPN Stoessel de Britto, embora sem autorização. O uso 
TABELA 2. Porcentagem de concordância quanto ao(s) uso(s) principal(is) (espécies citadas por cinco ou mais informantes). Convenções: ICUE - número de informantes citando uso da espécie; ICUP - número de informantes citando uso principal; CUP - índice de concordância de uso; FC - fator de correção; CUPc - CUP corrigida. (Adaptado de Pinto et al., 2006).

\begin{tabular}{|c|c|c|c|c|c|c|}
\hline Nome Científico & Uso Principal & ICUE & ICUP & CUP & FC & CUPc \\
\hline Myracrodruon urundeuva Allemão & inflamação & 12 & 10 & 83,3 & 1,0 & 83,3 \\
\hline Amburana cearensis (Allemão) A.C.Sm. & gripe, sinusite & 12 & 9 & 75,0 & 1,0 & 75,0 \\
\hline Heliotropium elongatum Willd. & gripe & 11 & 9 & 81,8 & 0,9 & 75,0 \\
\hline Gomphrena demissa Mart. & gripe & 10 & 9 & 90,0 & 0,8 & 75,0 \\
\hline Cleome spinosa Jacq. & gripe & 10 & 9 & 90,0 & 0,8 & 75,0 \\
\hline Hyptis suaveolens (L.) Poit. & estalicido, gripe & 9 & 9 & 100,0 & 0,8 & 75,0 \\
\hline Vitex gardneriana Schauer & verminose & 8 & 8 & 100,0 & 0,7 & 66,7 \\
\hline Croton blanchetianus Baill. & gripe & 7 & 7 & 100,0 & 0,6 & 58,3 \\
\hline Operculina macrocarpa (Linn) Urb. & verminose & 10 & 7 & 70,0 & 0,8 & 58,3 \\
\hline Luffa operculata (L.) Cogn. & sinusite & 7 & 6 & 85,7 & 0,6 & 50,0 \\
\hline Cnidoscolus quercifolius Pohl. & dor de dente & 7 & 6 & 85,7 & 0,6 & 50,0 \\
\hline Phyllanthus niruri L. & doença dos rins & 6 & 6 & 100,0 & 0,5 & 50,0 \\
\hline Ziziphus joazeiro Mart. & gripe & 9 & 6 & 66,7 & 0,8 & 50,0 \\
\hline Scoparia dulcis L. & rouquidão & 10 & 5 & 50,0 & 0,8 & 41,7 \\
\hline Turnera subulata Sm. & tumor & 10 & 5 & 50,0 & 0,8 & 41,7 \\
\hline Acanthospermum hispidum DC. & tosse & 5 & 5 & 100,0 & 0,4 & 41,7 \\
\hline Mimosa tenuiflora (Willd.) Poir. & inflamação & 11 & 5 & 45,5 & 0,9 & 41,7 \\
\hline $\begin{array}{l}\text { Sideroxylon obtusifolium (Humb. ex Roem. } \\
\text { \& Schult.) T.D. Penn. }\end{array}$ & inflamação & 8 & 5 & 62,5 & 0,7 & 41,7 \\
\hline Apodanthera congestiflora Cogn. & depurativo do sangue & 7 & 4 & 57,1 & 0,6 & 33,3 \\
\hline Caesalpinia ferrea Mart. & doença dos rins & 7 & 4 & 57,1 & 0,6 & 33,3 \\
\hline Cnidoscolus urens (L.) Arthur & dor de dente & 5 & 4 & 80,0 & 0,4 & 33,3 \\
\hline Caesalpinia pyramidalis Tul. & gripe & 5 & 4 & 80,0 & 0,4 & 33,3 \\
\hline Boerhavia diffusa $\mathrm{L}$ & depurativo do sangue & 5 & 4 & 80,0 & 0,4 & 33,3 \\
\hline Anadenanthera colubrina (Vell.) Brenan & gripe & 8 & 4 & 50,0 & 0,7 & 33,3 \\
\hline Melocactus sp. & bronquite & 6 & 4 & 66,7 & 0,5 & 33,3 \\
\hline Ximenia americana $\mathrm{L}$. & inflamação & 7 & 3 & 42,9 & 0,6 & 25,0 \\
\hline Chenopodium ambrosioides L. & fratura, gastrite & 5 & 3 & 60,0 & 0,4 & 25,0 \\
\hline Jatropha mollissima (Pohl) Baill. & picada de cobra & 5 & 3 & 60,0 & 0,4 & 25,0 \\
\hline
\end{tabular}

de técnicas incorretas para a retirada de produto vegetal (principalmente cascas) é um dos principais problemas enfrentados pela RPPN, uma vezque essa atividade compromete a sobrevivência do espécime após a coleta. O curto período de realização entre uma coleta e outra, também contribui para a degradação da vegetação local.

Os entrevistados utilizam os recursos obtidos da vegetação nativa para seu próprio consumo, raramente transformando esses recursos em produtos de venda e troca. Buscam diretamente no "mato" o que precisam para a produção de remédios caseiros.
As partes das plantas mais utilizadas pelos entrevistados no município de Laginhas foram as cascas e as raízes, que são usadas principalmente no tratamento de doenças respiratórias, inflamações e doenças infecciosas e parasitárias, sendo estas consumidas em forma de infusos, xaropes (também chamado de lambedor) e maceração (Tabela 3). Diferentemente, em trabalhos realizados em outras áreas de Caatinga como Albuquerque \& Andrade (2002b), Franco \& Barros (2006) e Teixeira \& Melo (2006), as folhas estavam entre as partes mais citadas no preparo dos remédios. Essa divergência de resultados pode ser explicada devido à ausência 
de folhas, na maior parte do ano, nas espécies nativas do semi-árido e que esses autores abrangeram também espécies cultivadas em seus estudos (tendo essas folhas durante todo $o$ ano).

Existem formas de preparo dos remédios utilizados pelos especialistas locais que fogem dos métodos convencionais de preparo. Das cascas do cumaru (Amburana cearensis), são feitas balas que são muito apreciadas por crianças e adultos, mas que são remédios para sinusite. A raizda batata-depurga (Operculina macrocarpa) é consumida na forma de doce (indicado como estimulante de apetite) ou na forma de goma que é misturada na alimentação e que serve para verminose.

Durante as coletas das partes vegetais utilizadas na fabricação dos remédios, verificou-se que existem rituais que são cumpridos metodicamente pelos coletores para que o remédio funcione. Na coleta da raiz do xique-xique (Pilosocereus gounellel), só se pode coletar três raízes e estas têm que estar voltadas para o nascente do sol. Ao se fazer o banho contra manchas na pele com a raiz da cabeça-de-negro (Apodanthera congestiflora), necessita-se saber o sexo da planta para poder fazer a devida correspondência com o paciente; já no preparo da lavagem de queimaduras coma água das raspas do juazeiro (Ziziphus joazeiro), recomenda-se a retirada de nove conchas de espumas para descarte antes de banhar os locais atingidos. Esses rituais que aparentemente são sem importância ao senso comum e que não são explicados pelos informantes quando estes são questionados, devem sertestados em laboratório para a comprovação de sua eficácia.

Não há entre os informantes um armazenamento das plantas que desaparecem nos períodos da seca, e nem o cultivo em casa das herbáceas nativas. $\mathrm{Na}$ comunidade há o cultivo de plantas exóticas, que também são bastante usadas no tratamento de doenças, mas que não contempla a abrangência desta pesquisa.

Foi observado que algumas plantas tiveram propriedades terapêuticas descobertas através da observação da população em animais da região. É o caso do mororó-preto (Bauhinia cheilantha) e do pinhão-bravo (Jatropha mollissima). Segundo relatos, o mororó-preto teve o uso associado ao combate de hemorragias depois que alguns caçadores notaram que um grupo de macacos que habitam a RPPN Stoessel de Britto socorria os membros do grupo que eram atingidos por balas com folhas de mororó-preto. As folhas desta espécie passaram, desde então, a serem usadas para tratamento de pequenos cortes. Já o uso do pinhão-bravo foi associado ao combate de picadas de cobra, depois de ser observado várias vezes que o "tejo" (Tupinambi merianae) enfrentava cobras peçonhentas e, quando era picado, mordia o pinhão para beber seu látex, retornando à luta logo após, quando sempre vencia. Determinou-se então o látex desta planta como um antídoto ao veneno das cobras. Oleite do pinhão-bravo embora seja altamente tóxico, já foi consumido dentro da comunidade mais de uma vez neste caso específico, e os resultados, segundo os moradores, levaram à cura do doente.

Os informantes foram questionados sobre as principais doenças que afetam as suas famílias e que podemser tratados através das plantas medicinais. As respostas evidenciaramque os entrevistados não fazem distinção entre doenças e sintomas. As doenças e os sintomas foram separados por categorias de acordo como CID 10 - Classificação Estatística Internacional de Doenças e Problemas Relacionados à Saúde (OMS, 2000). As doenças relacionadas ao aparelho respiratório foramas mais citadas pelos entrevistados, dando-se destaque a gripe, doenças mais lembrada nas entrevistas.

A Tabela 4 mostra a porcentagem de citações de cada categoria de doença e a doença mais citada dentro da categoria.

Constatou-se, neste levantamento, que além das doenças aceitas pela medicina convencional, existiam doenças que causavam estado de desconforto emocional, mas que não eram reconhecidas pela biomedicina (quebrante, arcacaída, força de dente, encosto, feitiço, peito-aberto, vista quebrada) e como proposto por Amorozo (2001), enquadraram-se como "doenças culturais". As doenças culturais são bastante populares em comunidades rurais, e servem para explicar sintomas de outras doenças que não foram identificadas pela população naquele momento especifico.

Em relação a como foram adquiridos os saberes sobre as plantas medicinais e seus usos, todos os entrevistados concordaram que aprenderam com os familiares mais idosos.

Há entendimento dos entrevistados sobre a importância deste trabalho, uma vez que estes são cientes de que as plantas medicinais utilizadas atualmente por eles estão reduzindo consideravelmente seu número em relação às formas de uso. As facilidades trazidas pelo atendimento médico, os remédios de farmácia e outras comodidades proporcionadas pela modernidade atraem os mais jovens, que abandonam ou optam por deixar de conhecer a sabedoria popular de seus pais e/ou avós.

Os informantes reconhecem que as plantas utilizadas por eles, a cada dia que passa, ficam mais escassas e atribuem tal fato à busca indiscriminada desses recursos. São pessoas que acreditam no poder terapêutico das plantas e que desconfiam da medicina convencional.

A partir dos resultados de trabalhos com plantas medicinais, o pesquisador pode e deve traçar planos que contemplema recuperação e conservação

Rev. Bras. PI. Med., Botucatu, v.12, n.1, p.31-42, 2010. 
TABELA 3. Plantas medicinais citadas por especialistas locais na comunidade rural de Laginhas, Caicó - RN (em ordem alfabética), partes usadas, manipulação e principais doenças combatidas.

\begin{tabular}{|c|c|c|c|}
\hline Nome Científico & Partes Usadas & Manipulação & Doenças combatidas \\
\hline Acanthospermum hispidum DC. & raiz & xarope, infusão & gripe, tosse \\
\hline Amburana cearensis (Allemão) A.C.Sm. & casca, sementes & $\begin{array}{l}\text { xarope, maceração, pó, } \\
\text { 'balas' }\end{array}$ & $\begin{array}{c}\text { gripe, sinusite, dor de cabeça, } \\
\text { dores musculares, tosse, prisão } \\
\text { de ventre, tontisse }\end{array}$ \\
\hline Anadenanthera colubrina (Vell.) Brenan & $\begin{array}{l}\text { casca, resina, } \\
\text { entrecasca }\end{array}$ & xarope, infusão, maceração & $\begin{array}{l}\text { gripe, tuberculose, coqueluche, } \\
\text { tosse, fratura, peito aberto }\end{array}$ \\
\hline Apodanthera congestiflora Cogn. & raiz & banho, infusão, tintura, pó & $\begin{array}{c}\text { manchas de pele, sangue grosso, } \\
\text { coceira }\end{array}$ \\
\hline Aspidospema pyrifolium Mart. & casca & infusão & abortivo \\
\hline Bauhinia cheilantha (Bong.) Steud. & raiz & infusão & doença no rins \\
\hline $\begin{array}{l}\text { Bauhinia pentandra (Bong.) Vogel ex } \\
\text { Steud. }\end{array}$ & casca, entrecasca & infusão, maceração & inflamação, cicatrizante \\
\hline Boerhavia diffusa L. & raiz & maceração, infusão, xarope & espinha \\
\hline Caesalpinia ferrea Mart. & fruto & $\begin{array}{l}\text { maceração, tintura, infusão, } \\
\text { decocção }\end{array}$ & $\begin{array}{c}\text { doença dos rins, inflamação, } \\
\text { cicatrizante, inflamação na uretra, } \\
\text { pancada }\end{array}$ \\
\hline Caesalpinia pyramidalis Tul. & flor, casca & xarope & gripe \\
\hline Capparis cynophallophora L. & fruto & maceração & ferimentos \\
\hline Cereus jamacan DC. & toda a planta, raiz & banho, infusão, maceração & ferimentos, inflamação da uretra \\
\hline Chenopodium ambrosioides $\mathrm{L}$. & folhas & suco & $\begin{array}{c}\text { úlcera, gas trite, pancada, fraturas, } \\
\text { câncer, gripe }\end{array}$ \\
\hline Cleome spinosa Jacq. & flor, raiz & xarope, infusão, maceração & gripe, dor de ouvido, tosse \\
\hline Cnidoscolus quercifolius Pohl & $\begin{array}{l}\text { casca, látex, } \\
\text { entrecasca }\end{array}$ & $\begin{array}{c}\text { maceração, banho, in } \\
\text { natura }\end{array}$ & $\begin{array}{c}\text { ferimentos, dor de dente, dor de } \\
\text { coluna }\end{array}$ \\
\hline Cnidoscolus urens (L.) Arthur & raiz, entrecasca & infusão & $\begin{array}{c}\text { inflamação na próstata, doença } \\
\text { dos rins, apendicite }\end{array}$ \\
\hline Combretum leprosum Mart. & casca & maceração, infusão & dor de barriga \\
\hline $\begin{array}{l}\text { Commiphora leptophloeos (Mart.) J.B. } \\
\text { Gillett }\end{array}$ & casca & maceração, banho & ferimentos \\
\hline Copernicia cerifera (Arruda) Mart. & raiz & infusão, maceração & inflam ação na uretra \\
\hline Croton blanchetianus Baill. & casca, entrecasca & xarope, infusão & gripe, dor de barriga \\
\hline Croton heliotropiifolius Kunth. & raiz, látex & infusão, uso tópico & dor de coluna \\
\hline Croton sp. & casca & xarope & gripe \\
\hline Cypenus articulatus $\mathrm{L}$ & raiz & infusão & dor de coluna \\
\hline Dioclea grandiflora Mart. ex Benth. & semente, casca & amuleto, infusão & força de dente, dor de dente \\
\hline Echinodorus subalatus (Mart.) Griseb & folha & infusão, xarope & dor de cabeça, enxaqueca \\
\hline Egletes viscosa (L.) Less. & fruto & infusão, in natura & má digestão \\
\hline Erythrina velutina Willd. & casca & infusão & dor de dente \\
\hline Fimbristylis vahlii (Lam.) Link & raiz & infusão & doença dos rins \\
\hline Geoffroea spinosa Jacq. & casca & maceração & anemia \\
\hline Gomphrena demis sa Mart. & raiz & xarope, infusão, maceração & gripe \\
\hline Guettarda angelica Mart. ex Müll.Arg. & casca & xarope, chá & febre \\
\hline Heliotropium elongatum Willd. & flor, raiz & xarope, infusão & gripe, tosse \\
\hline Hybanthus calceolaria (L.) Oken & toda planta & xarope, infusão, maceração & gripe, veme \\
\hline Hyptis suaveolens (L.) Poit. & toda a planta & inalação, infusão, banho & $\begin{array}{c}\text { estalicido, doenças respiratórias, } \\
\text { gripe }\end{array}$ \\
\hline $\begin{array}{l}\text { Ipomoea asarifolia (Desr.) Roem. \& } \\
\text { Schult. }\end{array}$ & toda a planta & banho & coceira, inflamação dos dentes \\
\hline Jatropha mollissima (Pohl) Baill. & látex, folhas & in natura, compressa & picada de cobra \\
\hline Licania rigida Benth & folha & maceração & doenças dos rins, emagrecer \\
\hline Luffa operculata (L.) Cogn. & fruto & infusão & $\begin{array}{l}\text { sinusite, estalicido, abortivo, } \\
\text { caspa, seborréia }\end{array}$ \\
\hline $\begin{array}{l}\text { Marsypianthes chamaedrys (Vahl) } \\
\text { Kuntze }\end{array}$ & toda a planta & banho & reumatismo \\
\hline Melocactus sp. & fruto, água & xarope, in natura & $\begin{array}{l}\text { pneumonia, gripe, doenças } \\
\text { respiratórias, tosse, bronquite }\end{array}$ \\
\hline Mimosa tenuiflora (Willd.) Poir. & $\begin{array}{l}\text { casca, flor, } \\
\text { entrecasca }\end{array}$ & $\begin{array}{l}\text { maceração, xarope, infusão, } \\
\text { decocção }\end{array}$ & $\begin{array}{c}\text { inflamação, dor de barriga, gripe, } \\
\text { ferimentos }\end{array}$ \\
\hline Myracrodruon urundeuva Allemão & casca, entrecasca & $\begin{array}{l}\text { xarope, maceração, tintura, } \\
\text { infusão, banho }\end{array}$ & $\begin{array}{c}\text { câncer, inflamação, dor de } \\
\text { garganta, doença renal, coluna, } \\
\text { útero, ferimento }\end{array}$ \\
\hline Myroxylon peruiferum $L \mathrm{f}$. & casca, resina & $\begin{array}{c}\text { maceração, infusão, banho, } \\
\text { xarope }\end{array}$ & dor de coluna \\
\hline
\end{tabular}


TABELA 3. Plantas medicinais citadas por especialistas locais na comunidade rural de Laginhas, Caicó - RN (em ordem alfabética), partes usadas, manipulação e principais doenças combatidas.

...continuação

\begin{tabular}{|c|c|c|c|}
\hline Nome Científico & Partes Usadas & Manipulação & Doenças combatidas \\
\hline Operculina macrocarpa (Linn) Urb. & raiz & "doce", xarope, pó, infusão & $\begin{array}{l}\text { verminose, catarro, doenças } \\
\text { respiratórias, falta de apetite }\end{array}$ \\
\hline Passiflora foetida L. & fruto & suco & insônia \\
\hline Phyllanthus niruri L. & raiz & infusão & doença dos rins \\
\hline $\begin{array}{l}\text { Pilosocereus gounellei (F.A.C. Weber) } \\
\text { Byles \& G.D. Rowley }\end{array}$ & raiz & maceração & inflamação na uretra \\
\hline $\begin{array}{l}\text { Pseudobombax marginatum (A. St.-Hil., } \\
\text { Juss. \& Cambess.) A. Robyns }\end{array}$ & entrecasca & maceração & dor de coluna \\
\hline Scoparia dulcis $\mathrm{L}$. & folhas, raiz & $\begin{array}{l}\text { xarope, infusão, maceração, } \\
\text { ramo }\end{array}$ & $\begin{array}{l}\text { gripe, asma, machucado, fraturas, } \\
\text { mal olhado, quebrante }\end{array}$ \\
\hline Selaginella convoluta (Arn.) Spring & folhas & infusão & icterícia \\
\hline $\begin{array}{l}\text { Senna obtusifolia (L.) H.S. Irwin \& } \\
\text { Barneby }\end{array}$ & flores & xarope & gripe \\
\hline Senna ocidentallis (L.) Link & raiz & infusão & aborto, cólica mens trual \\
\hline $\begin{array}{l}\text { Sideroxylon obtusifolium (Humb. ex } \\
\text { Roem. \& Schult.) T.D. Penn. }\end{array}$ & entrecasca, casca & $\begin{array}{c}\text { xarope, maceração, infusão, } \\
\text { banho }\end{array}$ & dor, pancada, inflamação \\
\hline Solanum agrarium Sendtn. & fruto, raiz & xarope, infusão & tosse \\
\hline Solanum sp. & folha & maceração, infusão & $\begin{array}{l}\text { verminose, cicatrizante, } \\
\text { inflamação }\end{array}$ \\
\hline $\begin{array}{l}\text { Tabebuia impetiginosa (Mart. ex DC.) } \\
\text { Standl. }\end{array}$ & casca, entrecasca & $\begin{array}{l}\text { pó, xarope, banho, } \\
\text { maceração }\end{array}$ & câncer, ferimento \\
\hline $\begin{array}{l}\text { Tocoyena formosa (Cham. \& Schltdl.) K. } \\
\text { Schum. }\end{array}$ & casca & maceração & machucados \\
\hline Triplaris gardneriana Wedd. & casca & xarope, infusão & gastrite, úlcera \\
\hline Turnera subulataSm. & raiz, flor, tintura & $\begin{array}{l}\text { banho, maceração, infusão, } \\
\text { compressa }\end{array}$ & $\begin{array}{c}\text { coceira, tumor, gripe, cortes, } \\
\text { abortivo } \\
\text { verminose, gripe, estalicido, }\end{array}$ \\
\hline Vitex gardneriana Schauer & folhas & xarope, infusão & $\begin{array}{l}\text { gases, dor de barriga, sinusite, } \\
\text { inflamação na próstata }\end{array}$ \\
\hline Ximenia americana L. & entrecasca, casca & $\begin{array}{c}\text { xarope, maceração, infusão, } \\
\text { pó, banho }\end{array}$ & inflamação, prisão de ventre \\
\hline Ziziphus joazeiro Mart. & casca & maceração, banho, xarope & $\begin{array}{l}\text { verminose, gripe, higiene bucal, } \\
\text { caspa, cicatrizante }\end{array}$ \\
\hline
\end{tabular}

TABELA 4. Porcentagem de citação para cada categoria $(n=506)$ e doença mais citada para cada categoria.

\begin{tabular}{|c|c|c|}
\hline Categorias & \% de citações & Doença mais citada dentro da categoria \\
\hline Doenças do aparelho respiratório & $31,6 \%$ & gripe \\
\hline $\begin{array}{l}\text { Sintomas, sinais e achados anomais de exames clínicos e de laboratório, } \\
\text { não classificados em outra parte }\end{array}$ & $17,6 \%$ & inflamação \\
\hline Algumas doenças infecciosas e parasitárias & $9,5 \%$ & verminose \\
\hline $\begin{array}{l}\text { Lesões, envenenamento e algumas outras conseqüências de causas } \\
\text { externas }\end{array}$ & $9,1 \%$ & ferimentos \\
\hline Doenças do aparelho geniturinário & $8,9 \%$ & doença dos rins \\
\hline Doenças do aparelho digestivo & $5,7 \%$ & cánie \\
\hline Doenças da pele e do tecido subcutâneo & $3,2 \%$ & coceira \\
\hline $\begin{array}{l}\text { Doenças do sangue e dos órgãos hematopoéticos e alguns transtornos } \\
\text { imunitários }\end{array}$ & $3,0 \%$ & sangue grosso \\
\hline Gravidez, parto e puerpério & $2,8 \%$ & indução de aborto \\
\hline Doenças do sistema osteomuscular e do tecido conjuntivo & $1,8 \%$ & dor de coluna \\
\hline Neoplasias [tumores] & $1,6 \%$ & câncer \\
\hline OUTROS & $1,6 \%$ & higiene bucal \\
\hline Doenças do ouvido e da apófise mastóide & $1,4 \%$ & dor de ouvido \\
\hline Causas externas de morbidade e de mortalidade & $0,6 \%$ & picada de cobra \\
\hline Doenças culturais & $0,6 \%$ & quebrante \\
\hline Doenças endócrinas, nutricionais e metabólicas & $0,6 \%$ & diabetes \\
\hline Doenças do sistema nervoso & $0,6 \%$ & enxaqueca \\
\hline
\end{tabular}

Rev. Bras. PI. Med., Botucatu, v.12, n.1, p.31-42, 2010. 
da área estudada, propondo novas práticas de manejo da vegetação, substituições de plantas com valores terapêuticos iguais, auxílio na armazenagem e no cultivo destas espécies. Esses esforços resultariam na otimização dos usos medicinais atribuídos pelos moradores como forma de complemento da renda da população, ao mesmo tempo em que se ampliariam as perspectivas das gerações futuras usufruírem destes recursos.

\section{AGRADECIMENTO}

À comunidade de Laginhas pela hospitalidade e receptividade durante os trabalhos de campo e pelos momentos de grande aprendizado. À senhora Lydia Brasileira de Britto, proprietária da RPPNStoessel de Britto, pelo acolhimento e pela indispensável contribuição e dedicação na realização deste trabalho.

\section{REFERÊNCIA}

ALBUQUERQUE, U.P.;ANDRADE, L.H.C. Conhecimento botânico tradicional e conservação em uma área de caatinga no estado de Pernambuco, Nordeste do Brasil. Acta Botanica Brasilica, v.16, n.3, p.273-85, 2002a. ALBUQUERQUE, U.P.; ANDRADE, L.H.C. Uso de recursos vegetais da Caatinga: o caso do agreste do estado de Pernambuco (Nordeste do Brasil). Interciência, v.27, n.7, p.336-46, 2002b.

ALBUQUERQUE, U.P. Introdução à etnobotânica. 2.ed. Rio de Janeiro: Editora Interciência, 2005. 93p.

ALBUQUERQUE, U.P.; LUCENA, R.F.P. Métodos e técnicas de pesquisa etnobotânica. Recife: LivroRápido/ NUPEEA, 2004. 189p.

AMOROZO, M.C.M.; GÉLY, A.L. Uso de plantas medicinais por caboclos do Baixo Amazonas. Boletim do Museu Paraense Emilio Goeldi, Série Botânica, v.4, n.1, p.47131, 1988.

AMOROZO, M.C.M. Uso e diversidade de plantas medicinais em Santo Antonio do Leverger, MT, Brasil. Acta Botanica Brasilica, v.16, n.2, p.189-203, 2001.

A.P.G. - Angiosperm Phylogeny Group II. An update of the Angiosperm Phylogeny Group classification for the orders and families of flowering plants:APG II. Botanical Journal of the Linnean Society, v.426, p.141-399, 2003. BAILEY, K. Methods of social research. 4.ed. New York: The Free Press, 1994. 588p.

IBGE. Instituto Brasileiro de Geografia e Estatística. Censo Demográfico. Brasília, 2000.

IBGE. Instituto Brasileiro de Geografia e Estatística. Manual Técnico da Vegetação Brasileira. Brasília, 1992. $81 \mathrm{p}$.

BRASIL. Ministério do Meio Ambiente. Instrução normativa n.6, de 23 de setembro de 2008. Reconhece espécies da flora ameaçada de extinção. Diário Oficial da União, Brasília, DF, 24 set. 2008. n.185.

BRASIL. Ministério do Meio Ambiente. Biodiversidade da caatinga: áreas e ações prioritárias para a conservação. Brasília: Ministério do Meio Ambiente e Universidade Federal de Pernambuco, 2002. 36p.

BRIDSON, D.; FORMAN, L. The herbarium handbook. Kew: The Royal Botanic Gardens, 1998. 732p.

CAMACHO, R.G.V. Estudo fitofisiográfico da caatinga do Seridó: estação ecológica do Seridó, RN. 2001.130p. Tese (Doutorado - Área de concentração em Botânica)Departamento de Botânica, Universidade de São Paulo, São Paulo.

DIEGUES, A.C. Etnoconservação da natureza: enfoques alternativos. In: DIEGUES, A.C. (Ed.) Etnoconservação: novos rumos para a proteção da natureza nos trópicos. São Paulo: Editora Hucitec, 2000. p.1-46.

FLORENTINO, A.T.N.;ARAÚJO, E.L.;ALBUQUERQUE, U.P. Contribuição de quintais agroflorestais na conservação de plantas da caatinga, município de Caruaru, PE, Brasil. Acta Botanica Brasilica, v.21, n.1, p.37-47, 2007.

FRANCO, E.A.P.;BARROS, R.F.M. Uso e diversidade de plantas medicinais no Quilombo Olho D'água dos Pires, Esperantina, Piauí. Revista Brasileira de Plantas Medicinais, v.8, n.3, p.78-88, 2006.

MOBOT - Missouri Botanical Garden. Disponível em: <http://www.tropicos.org >. Acesso em: 11 ago. 2008.

MORI, S.A. et al. Manual de manejo do herbário fanerogâmico. 2.ed. Ilhéus: Centro de Pesquisas do Cacau, 1989. 103p.

OMS - Organização Mundial de Saúde. Classificação estatística internacional de doenças e problemas relacionados à saúde. 10.ed. São Paulo: Editora da Universidade de São Paulo, 2000. 1191p.

PILLA, M.A.C.;AMOROZO, M.C.M.; FURLAN, A. Obtenção e uso de plantas medicinais no distrito de Martim Francisco, Município de Mogi Mirim, SP, Brasil. Acta Botanica Brasilica, v.20, n.4, p.789-802, 2006.

PINTO, E.P.P.; AMOROZO, M.C.M.; FURLAN, A. Conhecimento popular sobre plantas medicinais, em comunidades rurais, em área de Mata Atlântica - Itacaré, BA. Acta Botânica Brasílica, v.20, n.4, p.751-62, 2006. QUEIROZ, R.T. Diversidade florística do componente herbáceo daestação ecológica do Seridó,Serra Negra do Norte - RN. 2006. 66p. (Mestrado - Área de concentração em Botânica) - Departamento de Botânica, Ecologia e Zoologia, Centro de Biociências da Universidade Federal do Rio Grande do Norte, Natal. SANTOS, J.F.L.;AMOROZO, M.C.M.; MING, L.C. Uso de plantas medicinais na comunidade rural da Vargem Grande, município de Natividade da Serra, SP. Revista Brasileira de Plantas Medicinais, v.10, n.3, p.67-81,2008. TEXEIRA, S.A.; MELO, J.I.M. Plantas medicinais utilizadas no município de Jupi, Pemambuco, Brasil. Iheringia, v.61, n.1-2, p.5-11, 2006.

VARELA-FREIRE, A.A. Acaatinga hiperxerófila Seridó, a sua caracterização e estratégias para a sua conservação. São Paulo:EditoraACIESP, 2002. 39p. 